\title{
Understanding the programmatic and contextual forces that influence participation in a government-sponsored international student-mobility program
}

Laura W. Perna, Kata Orosz, Zakir Jumakulov, Marina Kishkentayeva, Adil Ashirbekov

Graduate School of Education

Abstract

Although prior research establishes the forces that "push" and "pull” students to participate in foreign study, the transferability of findings from earlier studies is limited by the absence of theoretical grounding. In addition, relatively little is known about how a government-sponsored student mobility program promotes foreign study in a nation with a transitioning economy. Using case study methods, this study explores the characteristics of students who participate in such a program and identifies the programmatic characteristics and contextual forces that promote and limit participation. The findings shed light on the appropriate theoretical perspectives for understanding student participation in a government-sponsored mobility program and illustrate the need to consider how aspects of the national cultural, economic, and political context influence participation. The findings also raise several questions about how an international student mobility program should be structured to encourage participation and maximize benefits to individuals and society within a particular national context.

$\begin{array}{ll}\text { Original language } & \text { English } \\ \text { Pages (from-to) } & 173-188 \\ \text { Number of pages } & 16 \\ \text { Journal } & \text { Higher Education } \\ \text { Volume } & 69\end{array}$

Issue number 2

State Published - Feb 12015

Perna, L. W., Orosz, K., Jumakulov, Z., Kishkentayeva, M., \& Ashirbekov, A. (2015). Understanding the programmatic and contextual forces that influence participation in a government-sponsored international student-mobility program. Higher Education, 69(2), 173-188. DOI: 10.1007/s10734-014-9767-4 